\title{
ENSINAMENTOS CANDOMBLECISTAS NAS MINAS GERAIS
}

Adalberto de Salles Lima ${ }^{1}$

DOI: https://doi.org/10.26512/revistacalundu.v2i1.9556

Resenha do livro: NOGUEIRA, Nelson Mateus. O Moxicongo nas Minas Gerais: Raízes e Tradição. Cabana Senhora da Glória, 2017.

O livro O Moxicongo nas Minas Gerais: Raízes e Tradição de Nelson Mateus Nogueira é uma coletânea de ensinamentos e experiências de um homem religioso. Durante sua vida se dedicou ao fortalecimento das raízes cultural cultura afro-brasileira através da entrada do Candomblé Moxicongo em Minas Gerais, em 1966. Como pai de santo do Candomblé Angola, seu Nelson Nogueira possui a dijina (nome religioso) de Tateto Nepanji.

O livro está dividido em quinze momentos: Prefácio, Prólogo: De Nelson a Nepanji, Introdução, Nossas raízes, Candomblé - Uma Dádiva Afro-Brasileira, Hierarquia, Formação dos Fiéis e Aperfeiçoamento para o Candomblé, Como São Chamados os Inquices no Candomblé Moxicongo, Saudações, Súplicas aos Inquices, Lágrimas dos Inquices, Sonetos, O Poder dos Sacrifícios e Sacodimentos no Moxicongo, Normas para os Iniciados nas tradições do Candomblé Moxicongo nas Minas Gerais e o Posfácio.

O prefácio foi elaborado por Nilo Nogueira (Tata Kis'ange), Kivonda da Cabana Senhora da Glória - Nzo kuna Nkos'i, filho biológico de Tateto Nepanji. Nilo Nogueira apresenta alguns pontos sobre o terreiro Cabana Senhora da Glória e expõe seus afetos por seu pai, além de indicar que naquela casa praticava-se a Umbanda anteriormente ao Candomblé Moxicongo. Este passou a ser tocado/cultuado também, a partir de desígnios do mentor espiritual da casa, o preto velho Pai Guiné de Aruanda. No prólogo: De Nelson a Nepanji, Guilherme Dantas Nogueira (Tata Mub'nzazi), ogan da Cabana Senhora da Glória e neto biológico de Tateto Nepanji, fornece alguns detalhes: marcos históricos do Candomblé Moxicongo, parte da biografia de seu avô, a relação entre a entrada do Candomblé Moxicongo em Minas Gerais, em 1966, e as determinações de Pai Guine de Aruanda e do trabalho de Tateto Nepanji.

\footnotetext{
${ }^{1}$ Doutorando em Ciências Sociais - Estudos Comparados sobre as Américas pela Universidade de Brasília. Bolsista CAPES. sallesvitoria01@gmail.com
} 
Após os sentimentos positivos, afetos e pontos relevantes, situando o leitor acerca do Candomblé Moxicongo em Minas Gerais, por meio de parte da experiência de vida de Nelson Mateus Nogueira/Tateto Nepanji, brota a vontade de continuar a leitura.

$\mathrm{Na}$ introdução, Tateto Nepanji dedica o livro aos participantes do Candomblé e ressalta a importância central da religião na construção de felicidades das pessoas e o cuidado rigoroso da obra em expor somente o permitido dos sagrados fundamentos da religião, preservando a ética e o respeito. Destaca-se também as orientações recebidas daqueles que o influenciaram a vivenciar o candomblé na década de 1960, sendo eles sua Mãe de Santo Helena Dias Nascimento (Mameto Oloiá) e seu filho carnal Domiense Pereira Amorim (Tata Mebandu).

Essa experiência candomblecista se iniciou através dos assentamentos dos fundamentos desta religião em sua casa, a Cabana Senhora da Glória - a partir de então também chamada de Nzo Kuna Nkos'i. A tradição assentada na Cabana Senhora da Glória foi justamente o Candomblé Moxicongo, da nação religiosa candomblecista Congo-Angola.

Tateto Nepanji conta um pouco de sua vivência religiosa. Antes de se tornar candomblecista, buscou um centro espírita umbandista para frequentar e ampliar seus conhecimentos. Com isso, encontrou a Tenda Espírita Jesus Amor em 13 de maio de 1952, localizada no bairro da Concórdia em Belo Horizonte. Naquele tempo, Tateto Nepanji recebia o preto velho Pai Zeferino Rei Congo de Angola e chegou a ser vice-presidente da Tenda no início do ano de 1954. Tateto Nepanji permaneceu nessa casa até 1961, quando, por determinação de Pai Guiné de Aruanda, fundou a Cabana Senhora da Glória, de onde partiu, posteriormente, em busca da iniciação no Candomblé.

Em “Nossas Raízes”, o autor fala da entrada da tradição Moxicongo em Minas Gerais, especificamente em Belo Horizonte, quando foram assentados seus fundamentos na Cabana Senhora da Glória em 13 de maio de 1966. Segundo seu Nelson Nogueira, até então se percebia em Belo Horizonte a ausência do Candomblé e uma mistura de um pouco de várias outras religiões afro-brasileiras. Com a sua iniciação, Tateto Nepanji iniciou um processo de desabrochamento e transição de elementos espirituais da Umbanda para o Candomblé, influenciando outros umbandistas a escolherem o Candomblé Moxicongo como prática definitiva de sua fé.

Em “Candomblé - Uma Dádiva Afro-Brasileira”, Tateto Nepanji, um homem grato a sua religião, enfatiza as raízes africanas milenares do Candomblé, por ter contribuído significativamente para a prática de fé de milhares de pessoas no país. O Candomblé é um espaço de acolhimento, independente da classe social e raça/cor das pessoas. O pai de santo 
reflete sobre a relevância da manutenção da fé religiosa na geração de atividades comerciais no âmbito nacional e internacional.

Tateto Nepanji enfatiza não ser fundamento do Candomblé a discórdia, como afirmam alguns fanáticos religiosos neopentecostais. Ele observa a contradição entre a caridade apregoada em reuniões que colocam os neopentecostais fanáticos na condição de o verdadeiro Messias e a insatisfação em suas mentes doentias alimentadas, fomentadas por construções sociais enviesadas. Apesar disso, seu Nelson Nogueira se afasta de qualquer sentimento de vingança para afirmar: "A prestação de contas se dará sim, através de atos que dignifiquem a nossa alma e consciência e, o nosso procedimento deve ser correto e pacífico, pois somente com muito amor conseguiremos a verdadeira união de todos os candomblecistas e de todas as religiões" (p. 28).

$\mathrm{Na}$ "Herança", Tateto Nepanji ressalta "como em muitos aspectos da vida, aquele que hierarquicamente respeita o outro aprende muito mais" (p. 29). A hierarquia no Candomblé é fundamental na conservação de sua cultura religiosa e se materializa através do respeito ao mais velho. Os cargos hierárquicos se diferem nas casas de Candomblé. Na nação Moxicongo os cargos mais altos são do Tateto Kuna Nkis'i (Pai de Santo) ou Mameto Kuna Nkis'i (Mãe de Santo), sempre apenas um dos dois ocupando o cargo e sem distinção de gênero.

Em “Formação dos Fiéis e Aperfeiçoamento para o Candomblé”, seu Nelson Nogueira trata da formação e aperfeiçoamento dos fiéis, com base no médium iniciado e não dos frequentadores não iniciados nas tradições religiosas. Dentro do terreiro é necessária a conscientização da prática do equilíbrio emocional, tolerância e amor ao próximo, possibilitando a plena religiosidade. Para Seu Nelson Nogueira, o iniciante deve ter uma formação e aperfeiçoamento adequado para não haver desequilíbrio no seu processo de iniciação, no terreiro e no seu convívio com outras pessoas. Acredita ser necessário o perdão e pregar a não violência no combate à demanda (ataques energéticos recebidos).

Em “Como São Chamados os Inquices no Candomblé Moxicongo", o autor apresenta os Inquices - divindades de origem africana cultuadas no Brasil pelo Candomblé Angola. Os Inquices são forças da natureza - a natureza é a principal manifestação dessas divindades. $\mathrm{Na}$ "Súplicas aos Inquices”, há orações particulares a cada Inquice. Em "Lágrimas dos Inquices”, os textos trazem o lamento dos Inquices diante das tristezas do mundo. Os "Sonetos", posteriormente, reforçam elementos de agradecimento, superação, motivação, amor, fé e esperança. 
No subitem "O Poder dos Sacrifícios e Sacodimentos no Moxicongo", Tateto Nepanji explica a situação de muitas vezes os trabalhos de magia realizados pelos praticantes da religião são equivocados pelo insuficiente conhecimento do significado de cada material e isso implica nos perigos de não usar animais e folhas sadias levadas aos sacrifícios. Os materiais devem ser usados com cuidado para produzir efeitos positivos em todo o ritual do sacrifício e ao consulente (pessoa que busca o Pai de Santo/Mãe de Santo ou um médium para atendimento espiritual).

No subitem "Normas para os Iniciados nas tradições do Candomblé Moxicongo nas Minas Gerais", o autor se inspira em alguns fundamentos do livro "Maçonaria Mística" para refletir princípios orientadores de um bom comportamento do iniciado no Candomblé como: "iniciado deve evitar que entre quaisquer irmãos surjam questões pessoais ou campeie a maledicência, a inveja, a calúnia e a lisonja" (p. 65).

No Posfácio, Guilherme Nogueira encerra o livro evidenciando a oportunidade de aprendermos com as memórias e experiências vividas do Tateto Nepanji, responsável por popularizar o Candomblé Angola nas Minas Gerais, ao continuar um movimento religioso de longa duração histórica nas Minas Gerais. Esse movimento tem antecedentes, a exemplo de Mãe Luzia Pinta em seu Calundu colonial no século XVIII. Ao concluir, Guilherme Nogueira observa algumas semelhanças entre processos históricos vividos entre o Moxicongo reorganizado por Pai Nepanji em irmandade com a Umbanda nas Minas gerais e o Calundu de Mãe Luzia.

Para quem o conhece com intimidade, como Nilo e Guilherme, Tateto Nepanji "[...] é um homem simples, humilde, marido exemplar e honrado, grande pai de família, avô em todo seu esplendor, fiel e leal à sua fé e seus amigos. Justo no discernimento dos seus atos” (p. 07). No meu caso, na condição de um jovem leitor, as memórias de resistência, amor e fé de seu Nelson lidas nesse livro ajudam a criar e fortalecer laços de afeto e solidariedade entre sujeitos e religião historicamente perseguidos pelo Estado.

Seu Nelson é um homem sábio, amado por sua família e dedicado à sua fé. Tateto Nepanji dedicou à autobiografia analisada aos participantes do Candomblé. Após a leitura do referido material, destaco pelo menos cinco palavras que alicerçam os sentimentos percebidos na obra: Candomblé, Gratidão, Respeito, Amor e Família.

O livro reúne aspectos particulares: não é de natureza acadêmica; possui valor sociocultural ao contribuir para o conhecimento do Candomblé Moxicongo, particularmente em sua forma praticada em Minas Gerais; referência para o campo dos estudos antirracistas ao 
mostrar problemáticas estruturais e em curso, como intolerância religiosa, discriminação e racismo. Também recomendo a leitura da obra aos sujeitos cujo espíritos intolerantes tem dificuldades de enxergar a diversidade cultural do mundo.

Para esses espíritos guiados por uma lógica de pensamento colonialista o mundo tem uma estrutura hierárquica inquestionável. Isso é um dos resultados do universalismo europeu. Diferentemente, para nós, sobretudo as populações negras de religião afro-brasileira, as relações humanas e seus aspectos culturais são intermediados por uma palavra muito usada na obra por seu Nelson Nogueira: respeito. Tal palavra traz a noção de um mundo visto horizontalmente. O respeito é a condição imprescindível contra a intolerância religiosa.

Por fim, o livro mostrou que a memória de um homem negro, velho e religioso é fundamental para contar sobre experiências de vidas silenciadas pela negação da cultura negra na construção da sociedade brasileira. É mister considerar a importância de o povo de candomblé publicar livros sobre si mesmo, como mecanismos de autodefesa e combate ao racismo e intolerância religiosa. Apesar de essa resenha ter a finalidade de mostrar ao leitor os pontos principais da obra, não substitui o contato pessoal com Tateto Nepanji para ouvi-lo acerca de seu livro.

Recebido em: 15/02/2018

Aceito em: 30/05/2018 